\title{
Determination of Organic Volatile Impurities in Twenty-Three Different Coated Tablet Formulations Using Headspace Gas Chromatography with Flame Ionization Detection Technique
}

Abida Latif ${ }^{*}$, Humera Shafi Makhdoom², Muhammad Imran², Mohammad Mazhar ${ }^{3}$, Emman Anwar', Mohammad Sarwar² and Muhammad Ashraf Tahir

${ }^{1}$ Pharmaceutical Chemistry Department, University of the Punjab, Lahore, Pakistan

${ }^{2}$ Forensic Toxicology Department, Punjab Forensic Science Agency, Lahore, Pakistan

${ }^{3}$ Quality Assurance Manager, Oval Pharmaceuticals, Lahore, Pakistan

\begin{abstract}
Organic solvents are extensively used in manufacturing processes of pharmaceutical formulations that cannot be completely eliminated from the product due to physical and chemical barriers. These solvents have no therapeutic value and may be toxic to human body if intake exceeds the permitted daily exposure. Therefore, a simple and sensitive method for simultaneous determination of methanol, acetonitrile, methylene chloride, n-hexane, cyclohexane, xylene, chloroform, nitromethane, toluene and pyridine was developed and validated. Separation was achieved on HP-Innowax polyethylene glycol gas chromatographic column $(30 \mathrm{~m} \times 250 \mu \mathrm{m} \times 0.25 \mu \mathrm{m})$ using Agilent 7890B gas chromatograph equipped with Agilent 7697A headspace auto-sampler and flame ionization detector. Twenty-three marketed coated tablet formulations (containing diclofenac sodium, Loratadine or montelukast sodium as active ingredient) were tested for the presence of volatile organic impurities using this method. Excellent results were obtained, within the globally accepted validation reference values, particularly taking into account the low concentration levels were investigated in twenty-three coated tablet formulations.
\end{abstract}

Keywords: Volatile organic impurities; Headspace; Coated tablets; Gas chromatograph; Flame ionization detector

\section{Introduction}

Residual Solvents (RS), or Organic Volatile Impurities (OVI), are potential risk for quality and stability of drug products as well as human body if intake exceeds the permitted daily exposure. RS do not provide any therapeutic benefit and should be removed to the maximum possible level fulfilling quality based requirements as per ICH guideline which is one of the standards to control quality and purity of the pharmaceutical substance, excipients and drug products $[1,2]$. During manufacturing, tablet coating processes require use of organic solvents like methanol, methylene chloride or acetonitrile. In order to obtain a high-quality tablet coating it should be dried immediately. From this point of view, organic solvents are unquestionably better than water because they evaporate quicker. However, after drying some amounts can remain in a drug product [3-5]. The organic solvents differ in molecular weight, polarity and volatility. For complex matrices like coated tablets, headspace sampling is the simplest, fastest and cleanest method [6-8]. In the present study, the Agilent's automatic headspace sampler was used for analysing residual solvents. This headspace sampler heats the vial and gas phase is equilibrated with liquid phase. Vaporized sample from the headspace of vial is injected into the inlet of GC by the headspace auto-sampler. This process occurs at temperature and pressure above ambient conditions. This technique is simple, relatively inexpensive and minimizes the formation of artifacts $[9,10]$.

\section{Experimental Methods}

\section{Instruments and materials}

An Agilent 7890B Gas Chromatograph (GC) with 7697A Headspace auto-sampler was used in method development and validation. Headspace auto-sampler was set to multiple extraction mode with $80^{\circ} \mathrm{C}$, $90^{\circ} \mathrm{C}$ and $105^{\circ} \mathrm{C}$ temperature for oven, loop and transfer line respectively. GC was equipped with standard oven for temperature programming, split/splitless injection port and flame ionization detector. Separation was achieved on HP- Innowax polyethylene glycol gas chromatographic column $(30 \mathrm{~m} \times 250 \mu \mathrm{m} \times 0.25 \mu \mathrm{m})$ using nitrogen as a carrier gas. GC inlet temperature was set at $140^{\circ} \mathrm{C}$ with split ratio $10: 1$ and $250^{\circ} \mathrm{C}$ flame ionization detector temperature.

MS grade acetonitrile, cyclohexane, methanol, methylene chloride, toluene, o-xylene, m-xylene, p-xylene, n-hexane, chloroform, nitromethane, pyridine, dimethyl sulphoxide (DMSO) and HPLC grade water were purchased from Fischer Scientific Loughborough, England. Twenty-three different branded coated tablet formulations were purchased from Health plus pharmacy, Sheikhupura.

\section{Preparation of standard stock solution A}

A standard stock solution A was prepared by adding $132 \mu \mathrm{L}$ Acetonitrile, $1250 \mu \mathrm{L}$ Cyclohexane, $950 \mu \mathrm{L}$ Methanol, $115 \mu \mathrm{L}$ methylene chloride, $256 \mu \mathrm{L}$ toluene, $380 \mu \mathrm{L}$ m-xylene, $56 \mu \mathrm{L}$ o-xylene and $90 \mu \mathrm{L}$ p-xylene in a $50 \mathrm{~mL}$ volumetric flask. Final volume was made up to the mark with dimethyl sulfoxide. The concentration of acetonitrile, cyclohexane, methanol, methylene chloride, toluene, m-xylene, o-xylene and p-xylene in standard stock solution A was 2050, 19400, $15000,3000,4450,6510,1520$ and 980 ppm respectively.

\section{Preparation of standard stock solution B}

A standard stock solution B was prepared by adding $110 \mu \mathrm{L}$ $\mathrm{n}$-hexane, $10 \mu \mathrm{L}$ chloroform, $11 \mu \mathrm{L}$ nitromethane and $50 \mu \mathrm{L}$ pyridine

*Corresponding author: Abida Latif, Head of Department, Pharmaceutical Chemistry Department, University of the Punjab, Allama Iqbal Campus, Lahore, Punjab, Pakistan, E-mail: abidalatifanwar@gmail.com

Received July 23, 2017; Accepted August 02, 2017; Published August 07, 2017

Citation: Latif A, Makhdoom HS, Imran M, Mazhar M, Anwar E (2017) Determination of Organic Volatile Impurities in Twenty-Three Different Coated Tablet Formulations Using Headspace Gas Chromatography with Flame Ionization Detection Technique. Pharm Anal Acta 8: 553. doi: 10.4172/2153-2435.1000553

Copyright: $\odot 2017$ Latif $A$, et al. This is an open-access article distributed unde the terms of the Creative Commons Attribution License, which permits unrestricted use, distribution, and reproduction in any medium, provided the original author and source are credited. 
Citation: Latif A, Makhdoom HS, Imran M, Mazhar M, Anwar E (2017) Determination of Organic Volatile Impurities in Twenty-Three Different Coated Tablet Formulations Using Headspace Gas Chromatography with Flame Ionization Detection Technique. Pharm Anal Acta 8: 553. doi: $10.4172 / 2153-2435.1000553$

Page 2 of 4

in a $50 \mathrm{~mL}$ volumetric flask. Final volume was made up to the mark with dimethyl sulfoxide. The concentration of n-hexane, chloroform, nitromethane and pyridine in standard stock solution B was 1450 , 3000,250 and 1000 ppm respectively.

\section{Preparation of working standard solution A}

A working standard solution A was prepared by diluting $1 \mathrm{~mL}$ of standard stock solution A with HPLC grade water in a $100 \mathrm{~mL}$ volumetric flask. Then $1 \mathrm{~mL}$ of working standard solution A was then transferred to a labeled headspace vial a $5 \mathrm{~mL}$ of water was then added to the vial which was immediately capped and mixed. The concentration of acetonitrile, cyclohexane, methanol, methylene chloride, toluene, $\mathrm{m}$-xylene, o-xylene and p-xylene in standard stock solution A was 20.5, $194,150,30,44.5,65.1,15.2$ and 9.8 ppm respectively.

\section{Preparation of working standard solution B}

A working standard solution B was prepared by diluting $1 \mathrm{~mL}$ of standard stock solution B with water in a $100 \mathrm{~mL}$ volumetric flask. Then $5 \mathrm{~mL}$ of working standard solution $\mathrm{B}$ was then transferred to a separate labeled headspace vial and $1 \mathrm{~mL}$ of water was then added to the vial which was immediately capped and mixed. The concentration of n-hexane, chloroform, nitromethane and pyridine in standard stock solution B was $72.5,150,12.5$ and 50 ppm respectively.

\section{Preparation of test sample}

Accurately weighed and crushed ten units in each brand of tablets. Average weight of crushed tablet powder (article under test) was transferred in to labeled headspace vial and added $5 \mathrm{~mL}$ of water and crimped properly. The sample was analyzed by HS-GC-FID.

\section{Preparation of spiked test sample}

Average weight of crushed tablet powder (sample positive for residual solvent) was transferred in to labeled headspace vial, added 5 $\mathrm{mL}$ water, spiked the relevant organic solvent at the target concentration (as in standard solution) and crimped properly. The spiked test sample was analyzed by HS-GC-FID.

\section{Preparation of negative control sample}

Negative control sample was prepared by adding $5 \mathrm{~mL}$ water into a headspace vial. Crimped the vial properly and analyzed by HS-GCFID.

\section{Analysis method}

Equal volumes of headspace $(1 \mathrm{~mL})$ of standard solutions and test samples were injected into the gas chromatograph; recorded the chromatograms and measured the responses for the major peaks. For test samples (positive for the residual solvents), spiked test samples were prepared and analyzed by HS-GC-FID. Amount (in ppm) for each residual solvent found in the test sample was calculated by using following formula:

$$
10(C / W)[r U / r S T-r U]
$$

Where:

C: Concentration of appropriate reference standard in the standard solution (in $\mu \mathrm{g} / \mathrm{mL}$ ).

W: Weight of test sample taken to prepare test stock solution (in g).

rU: Peak response of each residual solvent obtained from test solution.
rST: Peak response of each residual solvent obtained from spiked test solution.

\section{Method validation}

The analytical method validation was carried out as per ICH guidelines [2]. The validation parameters addressed were system suitability, precision, linearity, and accuracy, Limit of Detection (LOD), Limit of Quantification (LOQ), robustness and ruggedness.

System suitability: Six injections each of working standard solutions A and B were injected and Relative Standard Deviation (RSD) was calculated.

Precision: Accurately weighed and crushed ten units of each brand of tablets. $1 \mathrm{~g}$ of each brand of crushed powder mixed in a mortar. Then weighed $500 \mathrm{mg}$ of mixed tablet powder transferred into headspace vial and spiked and un-spiked samples by HS-GC-FID, concentration of each solvent was calculated and the true concentration was obtained by the subtracted value from the un-spiked sample.

Linearity: Linearity was established from the range of LOQ to $200 \%$ of the target concentration for each solvent. Linearity graph was plotted for each solvent and linear coefficient was determined.

LOD and LOQ establishment: LOD and LOQ were established by signal to noise $(\mathrm{S} / \mathrm{N})$ ratio method. $\mathrm{S} / \mathrm{N}$ ratio was found closer to 10 standard deviations for LOQ and 3 standard deviations for LOD.

Accuracy: Accuracy was established for LOQ to $200 \%$ of the target concentration after spiking the standard solution in the mixture of crushed formulations.

Robustness and ruggedness: Analytical parameters were deliberately changed and the system suitability was checked. GC Column was clipped, initial temperature of oven program and flow of the carrier gas $( \pm 2)$ were changed. Headspace parameters like oven loop and transfer line temperatures were also changed $( \pm 10 \%)$. For intermediate precision, experiment was performed by another analyst too.

\section{Results and Discussion}

In this study, a HS-GC-FID analytical method was developed and validated for the quantitative determination of the residual solvents in coated tablet formulations. The method was validated according to ICH guidelines and the summarized results of validation are reported in Table 1.

This validated method was applied to analyze residual solvents in twenty-three coated tablet formulations of national and multi-national origin available in the market. The typical gas chromatograms for standard solution A, standard solutions B and tablet test sample \# 9 are shown in Figures 1-3. The concentrations of residual solvents in these market products are determined in Table 2.

Residual solvents like methylene chloride, methanol, n-hexane, toluene and cyclohexane were detected in all tested tablets except sample \# 18. The concentration ranges of methylene chloride, methanol, n-hexane, toluene and cyclohexane found in these products were $122.16-313.73 \mathrm{ppm}$, 455.59-2155.53 ppm, 79.71-283-13 ppm, 132.76-487.13 ppm and 408.26-1069.52 ppm respectively. Although all products had passed the criteria for the presence of allowable concentration of residual solvents but a significant variation for type of solvents and their concentrations were observed among all tablets.

In montelukast sodium tablets $10 \mathrm{mg}$ (samples \# 1-8), methanol was detected in all tablets, $\mathrm{n}$-hexane in 7 , methylene chloride in 3 , 
Citation: Latif A, Makhdoom HS, Imran M, Mazhar M, Anwar E (2017) Determination of Organic Volatile Impurities in Twenty-Three Different Coated Tablet Formulations Using Headspace Gas Chromatography with Flame Ionization Detection Technique. Pharm Anal Acta 8: 553. doi: $10.4172 / 2153-2435.1000553$

Page 3 of 4

\begin{tabular}{|c|c|c|}
\hline Parameter & Acceptance criteria & Results \\
\hline System suitability & RSD not more than $15 \%$ & $1.5-7.4 \%$ \\
\hline Precision & $\begin{array}{c}\text { RSD (six sample preparation) } \\
\text { not more than } 15 \%\end{array}$ & $\begin{array}{l}\text { At LOQ level=7.5-12.3\% } \\
\text { At } 100 \% \text { level=3.1-7.6\% }\end{array}$ \\
\hline Accuracy & Percent recovery $(85-115 \%)$ & $\begin{array}{l}90 \text { to } 105 \% \text { (overall recovery } \\
\text { from LOQ to } 150 \% \text { ) }\end{array}$ \\
\hline Linearity & $\begin{array}{c}\text { Correlation coefficient not less } \\
\text { than } 0.985\end{array}$ & 0.997 to 0.999 \\
\hline LOD & 3 Standard deviation & $\begin{array}{l}\text { 6-25 ppm (for all RS in } \\
\text { standard solutions } A \text { and } B \text { ) }\end{array}$ \\
\hline LOQ & 10 Standard deviation & $\begin{array}{l}\text { 8-45 ppm (for all RS in } \\
\text { standard solutions } A \text { and } B \text { ) }\end{array}$ \\
\hline $\begin{array}{l}\text { Robustness and } \\
\text { Ruggedness }\end{array}$ & RSD not more than $15 \%$ & $\begin{array}{l}4.1-8.2 \% \text { (overall compilation } \\
\text { of system suitability) }\end{array}$ \\
\hline
\end{tabular}

Table 1: Summarized results of validation study.

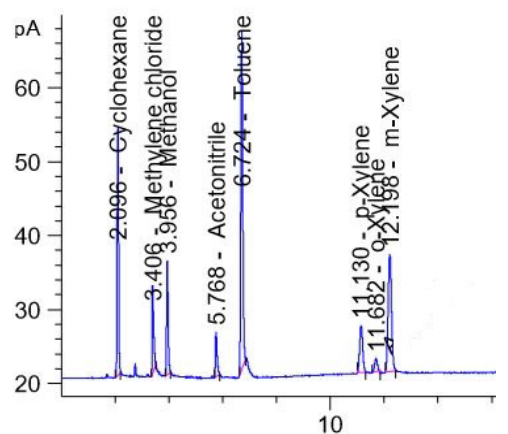

Figure 1: Gas chromatogram for working standard stock solution A.

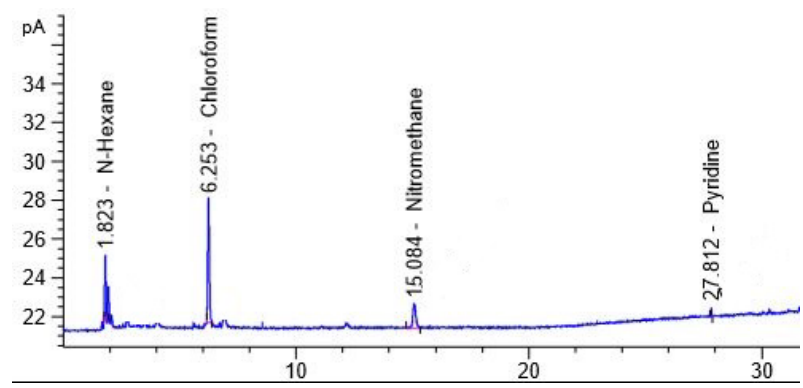

Figure 2: Gas chromatogram for working standard stock solution B.

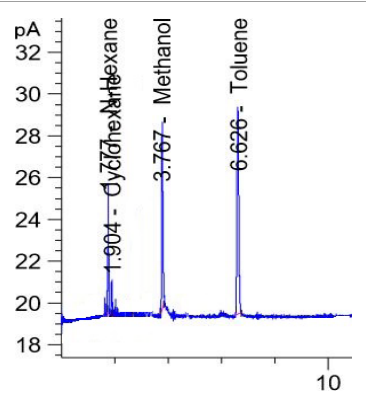

Figure 3: Gas chromatogram for Tablet test sample \# 9.

cyclohexane and toluene in 2 products. Similarly, in diclofenac sodium tablets $50 \mathrm{mg}$ (samples \# 9-16), n-hexane was detected in 7 tablets, methanol and cyclohexane in 3, toluene in 2 and methylene chloride was detected only in 1 product. In the same way, in Loratadine $10 \mathrm{mg}$ tablets (samples \# 17-23); n-hexane was detected in 6 tablets, while methanol, cyclohexane and toluene were detected only in 1 product.

\begin{tabular}{|c|c|c|c|}
\hline $\begin{array}{c}\text { Test } \\
\text { sample \# }\end{array}$ & $\begin{array}{c}\text { Average weight } \\
\text { of tablet taken (g) }\end{array}$ & $\begin{array}{l}\text { Residual solvents } \\
\text { detected }\end{array}$ & $\begin{array}{l}\text { Concentration of residual } \\
\text { solvent determined (ppm) }\end{array}$ \\
\hline \multirow{2}{*}{1} & \multirow{2}{*}{0.226} & Methylene chloride & 249.03 \\
\hline & & Methanol & 622.84 \\
\hline \multirow{3}{*}{2} & \multirow{3}{*}{0.216} & n-Hexane & 223.73 \\
\hline & & Methanol & 561.74 \\
\hline & & Toluene & 138.24 \\
\hline \multirow{4}{*}{3} & \multirow{4}{*}{0.211} & n-Hexane & 130.13 \\
\hline & & Methylene chloride & 211.54 \\
\hline & & Methanol & 526.16 \\
\hline & & Toluene & 174.76 \\
\hline \multirow{3}{*}{4} & \multirow{3}{*}{0.252} & n-Hexane & 283.13 \\
\hline & & Cyclohexane & 809.79 \\
\hline & & Methanol & 700.17 \\
\hline \multirow{3}{*}{5} & \multirow{3}{*}{0.182} & n-Hexane & 272.12 \\
\hline & & Cyclohexane & 1069.52 \\
\hline & & Methanol & 455.99 \\
\hline \multirow{2}{*}{6} & \multirow{2}{*}{0.208} & n-Hexane & 229.22 \\
\hline & & Methanol & 564.15 \\
\hline \multirow{4}{*}{7} & \multirow{4}{*}{0.206} & n-Hexane & 169.57 \\
\hline & & Cyclohexane & 888.19 \\
\hline & & Methylene chloride & 122.16 \\
\hline & & Methanol & 521.21 \\
\hline \multirow{2}{*}{8} & \multirow{2}{*}{0.214} & n-Hexane & 111.12 \\
\hline & & Methanol & 1361.07 \\
\hline \multirow{4}{*}{9} & \multirow{4}{*}{0.223} & n-Hexane & 79.71 \\
\hline & & Cyclohexane & 975.97 \\
\hline & & Methanol & 1578.52 \\
\hline & & Toluene & 487.13 \\
\hline \multirow{3}{*}{10} & \multirow{3}{*}{0.228} & n-Hexane & 158.53 \\
\hline & & Cyclohexane & 408.26 \\
\hline & & Methanol & 1149.75 \\
\hline \multirow{2}{*}{11} & \multirow{2}{*}{0.166} & $\mathrm{n}$-Hexane & 229.55 \\
\hline & & Methanol & 2155.53 \\
\hline 12 & 0.201 & n-Hexane & 165.06 \\
\hline 13 & 0.149 & n-Hexane & 198.92 \\
\hline 14 & 0.229 & Cyclohexane & 565.09 \\
\hline & & n-Hexane & 114.71 \\
\hline 15 & 0.157 & Methylene chloride & 313.73 \\
\hline & & Toluene & 132.76 \\
\hline 16 & 0.182 & $\mathrm{n}$-Hexane & 279.73 \\
\hline 17 & 0.151 & n-Hexane & 241.59 \\
\hline 18 & 0.151 & Cyclohexane & 829.94 \\
\hline 18 & 0.161 & Residual so & Ivents not detected \\
\hline 19 & & $\mathrm{n}$-Hexane & 83.58 \\
\hline 19 & 0.145 & Methanol & 877.28 \\
\hline 20 & 0.184 & n-Hexane & 202.44 \\
\hline 21 & 0.125 & n-Hexane & 197.10 \\
\hline 22 & 0.16 & n-Hexane & 117.92 \\
\hline & 0.136 & n-Hexane & 180.54 \\
\hline 23 & 0.136 & Toluene & 196.50 \\
\hline
\end{tabular}

Table 2: Concentration of residual solvents in twenty-three tablet formulation.

\section{Conclusion}

To the best of author's knowledge, scanty literature is available regarding multiple solvents exposures. In current study, multiple solvents were detected in most of tablets such as four organic volatile impurities (n-hexane, cyclohexane, methanol, methylene chloride) 
Citation: Latif A, Makhdoom HS, Imran M, Mazhar M, Anwar E (2017) Determination of Organic Volatile Impurities in Twenty-Three Different Coated Tablet Formulations Using Headspace Gas Chromatography with Flame Ionization Detection Technique. Pharm Anal Acta 8: 553. doi: $10.4172 / 2153-2435.1000553$

were found in samples \# 3, 7 and 9, three solvents (n-hexane, cyclohexane, methanol) were detected in samples \# 2, 4, 5, 10 and 15. Similarly two residual solvents (methylene chloride, methanol) were found in samples \# 1,6,8,11,17, 19 and 23. Although these organic solvents lie within allowable limits but their combined effect may have toxic consequences over long-term exposure. Furthermore, dosage regimes of these tablets are usually twice or thrice a day, in this scenario chance of detrimental outcomes due to exposure to organic impurities may also increase. This aspect is especially important for those products in which organic impurities concentration approaches to upper limits such as sample \# 11 (methanol=2155.53 $\mathrm{ppm}$ ) and sample \# 4 (n-hexane $=283.13 \mathrm{ppm})$. Therefore, further toxicity studies must be conducted taking into account exposure to multiple organic solvents and dosage regimes of pharmaceutical products.

\section{References}

1. US Pharmacopial convention (2000) United States Pharmacopoeia (24th edn.). US Pharmacopial Convention, Rockville, MD, USA p: 877.

2. ICH Harmonized Tripartite Guidelines (1997) Impurities: Guideline for residual solvents Q3C (R3). Current Step 4 Version.

3. Legrand S, Dugay J, Vial J (2003) Use of solid-phase micro-extraction coupled with gas chromatography for the determination of residual solvents in pharmaceutical products. J Chromatogr A 999: 195-201.
4. Dennis KJ, Josephs PA, Dokladalova J (1992) Proposed automated headspace method for organic volatile impurities (467) and other residual solvents. Pharm Forum 18: 2964-2972.

5. Puranik SB, Sharath S, Sanjay Pai PN (2012) Headspace Gas Chromatography analysis of residual solvent using EC-5 column. Int J Pharmacol Clin Res 1 : 22-27.

6. Ramos CS (2013) Development and validation head space chromatographic method for determination of residual solvents in five drug substance. Int $J$ Pharm Sci Invent 2: 36-41.

7. Anil Kumar V, Arvind G, Srikanth I, Srinivasarao A, Dharma Raju CH (2012) Novel analytical method development and validation for the determination of residual solvents in Amplodipine besylate by gas chromatography. Der Pharma Chemica 4: 2228-2238.

8. Varun Raj V, Pramod G, Naresh Babu N (2010) Estimation of residual solvents in Clopidogrel bisulphate by using chromatographic techniques. Indian J Res Pharm Biotechnol 1: 92-96.

9. Grodowska K, Parczewski A (2010) Analytical methods for residual solvents determination in pharmaceutical products. Acta Poloniae Pharmaceutica-Drug Research 67: 13-26.

10. Baliyan PK, Singh RP, Arora S (2009) Simultaneous estimation of residua solvents (Isopropyl Alcohol and Dichloromethane) in dosage form by GC-HSFID. Asian J Chem 21: 1739-1746. 